\title{
Implant Placement after Sinus Augmentation with Hydroxyapatite Bone Graft and Platelet Rich Fibrin Membrane Closure: A Report of 2 Cases
}

\author{
Mamthashri V \\ Department of Oral and Maxillofacial Surgery, Government Dental College and Research Institute, Bangalore, India
}

\begin{abstract}
Long standing period of edentulousnes, coupled with increased antral pneumatization in the maxillary posterior regionmakes the alveolar ridge unsuitable for implant placement due to insufficient bone height, density and volume.Maxillary sinus augmentation is a surgical procedure which aims to increase the amount of bone in the posterior maxilla in the area of the premolar and molar teeth, by lifting the lower Schneiderian membrane and placing a bone graft. The case reports presented here aims at the immediate placement of the implant after a sinus augmentation surgery with hydroxyapatite bone graft and platelet rich fibrin (PRF) membrane closure.
\end{abstract}

Keywords: Implant placement, Lateral sinus augmentation, hydroxyapatite bone graft and platelet-rich fibrin (PRF) membrane

\section{Introduction}

Severely resorbed maxillary bone in the posterior region is best improved by accessing the sinus from the lateral approach, lifting the sinus membrane and packing the space with bone grafts. The sinus augmentation procedure provides a way to increase the amount of available bone and the placement of longer implants[1]. The advantage of using Platelet rich fibrin (PRF) is that it has increased osteogenic ability, a simple preparation process, absence of extrinsic biological agents, and sustained release of growth factors[2].There are many studies conducted to reveal the potential of PRF to promote endosinusbone regeneration[3],[4] and to reduce healing time after sinus floor elevation[5].

Case 1:

A 53- year old male patient reported to the outpatient department with a chief complaint of missing upper back teeth.On clinical examination \#26 was missing as it was extracted due to caries and was not replaced for many years Figure 1.Radiographical assessment showed less bone in \#26 regions Figure 2.

Case 2:

The second case was a 65 -year old female with missing \#15, \#16 and \#17 and had a previous fixed partial denture spanning from \#14 to \#17 which had failed due to the fracture of 17. Radiographically, the orthopentamograph (OPG) revealed insufficient bone height in edentulous maxillary posterior region making it impossible for implant placement [Figure 3].

Both the patients had no significant extraoral or intraoral abnormalities. Routine laboratory investigations revealed no systemic abnormalities. Bone density showed D3 type of bone in both the cases according to Misch's classification[6]. Informed consent was taken prior to the procedure from the patient. As the patient in case 2 already had a failed fixed prosthesis, she wanted to avoid removable prosthesis due to its inconvenience and therefore implant placement was opted.

Surgical area was scrubbed and draped. The maxillary posterior segment was an aesthetised with buccal and palatal infiltration. After securing adequate anaesthesia of $2 \%$ lignocaine with 1:80,000 adrenaline, a buccal vestibular incision was made with anterior and posterior vertical releasing incisions for adequate exposure. A full thickness buccal flap was raised until the zygomatic buttress. A lateral bony window was created on the sinus wall using a micromotor driven handpiece with a physio-dispenser for continuous irrigation of the bone Figure 4Figure 5. The Schneiderian membrane was then detached from the sinus floor using sinus elevators. Implant site osteotomy done with membrane kept raised with negative pressure. Asand blasted acid etched, dual thread, implant of sufficient height was placed simultaneously with sinus augmentation Figure 4. A motor driver was used to place the implants completely in the socket. The space between the raised sinus lining and the floor of the sinuswas packed with one cc of cancellous particulate hydroxyapatite bone allograft. The bone graft was pushed more apically, which in turn elevated the sinus floor while seating the implant. Meanwhile, $10 \mathrm{ccs}$ of blood was drawn from the patient for each single implant. The blood is then centrifuged at $3000 \mathrm{rpm} 1$ for $10 \mathrm{~min}$. PRF layer is formed in between the platelet poor plasma in the top of the tube and the red blood cells in the bottom. Additional hydroxyapatatite bone graft was packed around the implant and the antrostomy site closed with PRF membraneFigure 6Figure 7. Resorbable sutures were used to close the flap after achieving hemostasis.

Post-operativeinstructions were given and the patients were prescribed antibiotics, analgesics and anti-histamines for 5 days. Post-operative OPG was taken to assess the position of the implant and the patients were recalled in 10 days for reevaluation and suture removal.The site was allowed to heal for 6 months. Then, a healing abutment was placed, followed by temporary restorationFigure 8 . A fused to metal crown (PFM) was cemented with zinc phosphate cement after a crown trial which was done 3 days earlier for case 1Figure 9

\section{Volume 6 Issue 12, December 2017}




\section{International Journal of Science and Research (IJSR) \\ ISSN (Online): 2319-7064}

Index Copernicus Value (2016): 79.57 | Impact Factor (2015): 6.391

and case 2 Figure 10.Patients were recalled every 2 weeks and for 1, 3, 6 and 12 months during the first year and annually thereafter. Clinical examination conducted at each visit showed no defects or discomfort with the implant or the abutment. Radiographic evaluation showed increased bone height with better bone density in the maxillary antrum after the sinus lift in case 1Figure 11 and for case 2Figure 12.

\section{Discussion}

There are several studies to document lateral sinus antrostomy procedures with the use of either autogenous or alloplastic bone graft with or without the use of PRF membrane for increasing new bone formation. These techniques allow one to increase bone volume in the posterior maxilla and the placement of longer implants. It is also observed that the implant survival rate is higher in those placed in grafted sinuses than in those placed in the posterior maxilla without sinus grafting[1]. Though Platelet-rich plasma (PRP) was among the first generation of platelet concentrates [2] used with autogenous bone or bone substitute in sinus augmentation but its effect was not significant [7-9]. Platelet-rich fibrin (PRF) is from the second generation of platelet concentrate products. Studies have shown that PRF has greater osteogenic ability, involves a simple preparation process, is devoid of extrinsic biological agents, and has sustained release of growth factors [5]. Previous studies have revealed the potential of PRF to promote endosinus bone regeneration $[3,4]$ and to reduce healing time after sinus floor elevation [5]. In our case bone height and density were significantly improved with the use of hydroxyapatite and PRF membrane. Hydroxyapatite is a ceramic bone substitute that has good osteogenic potential, excellent biocompatibility and is biodegradable, thus offers better advantage over autogenous bone in terms of avoiding a secondary surgical procedure and reducing patient's morbidity. To achieve a good anchorage and primary stability of the implant, a bone regeneration material like hydroxyapatite bone graft is essential. PRF was chosen in our study due to its potential osteogenic and neoangiogenic property with good template for binding of the bone graft particles

The placement of implant immediately during the surgical procedure with bone grafting helps better stability of implant in the early phase and implant-bone integration through bone regeneration and remodeling in the late phase. Studies have shown that the improper technique, in which a final drill with a diameter smaller than the implant diameter, obtains superior implant stability to the press-fit technique[10]. In our study we have used implant size sufficient to bear the load in the posterior region. It has been reported that implants designs with tapered shapes[11], deep threads[12] and surface roughness[13, 14], could achieve greater primary stability. Also implant with a larger surface area is proportional to the square of its diameter so a wide diameter implants could dramatically increase bone-implant contact, thus reinforcing primary stability. The bone-condensing technique was usedin our cases for better stability of the implant. We used a deep dual thread, rough surface implant of sufficient length (10-14 mm) and wide diameter (4.5 to $8.0 \mathrm{~mm}$ ) was chosen to increase mechanical support from the available surrounding bone.

To achieve the objective of greater sinus lift in our study, the following steps were followed:

1) The residual space between the sinus floor and the elevated sinus membrane space was packed with hydroxyapatite bone graft for increasing bone height and density,

2) PRF membrane was used beneath the bone core and sinus membrane might which served as a cushion during sinus lifting to dampen the compressive force by the osteotome and also to seal of the buccal antrostomy entrance,

3) The detachment of the Schneiderian membrane from the sinus floor was maximized by the use of lateral inlay antrostomy, and

4) The Schneiderian membrane was maintained at a high position due to the bone core located apical to the implant.

Due to bone resorption in the initial 6 months of grafting, a slight over-packing of the graft material is suggested. There isstudies which show either the use of bone grafts or the use of PRF solely, for the sinus augmentation. Studies have also been done earlier with the combination of both hydroxyapatite bone graft and PRF membrane in sinus lift procedures[15]. In our present study we also used a powerful combination of both which aided in placement of longer implants with a better implant anchorage with an increased amount of new bone formation and thus less resorption to some extent. The later phase of bone resorption is minimal in the later phase of remodeling seen after 6 months after implant placement. This technique of sinus augmentation with graft and PRF membrane helps in placement of longer implant length and diameter giving a better mechanical stability and hence good success rate of implant. A good patient selection, proper per-operative assessment, skillful surgical technique, a good postoperative care and a long term follow up period are also important factors for the long term stability and success of an implant.

\section{Conclusion}

As increased sinus pneumatization due to prolonged edentulousness leaves behind very little bone height and density for the placement of the implant, immediate implant placement after a lateral sinus antrostomy in conjunction with the use of hydroxyapatite bone graft and PRF membrane showed a good success in our cases. However more sample size is also required to further substantiate our findings. A good success of the dental implant with sinus augmentation also depends on the proper patient selection, skill of the operator and a proper technique along with the suitable grafts chosen and a long term follow up of the cases.

\section{Financial support and sponsorship}

Nil.

\section{Volume 6 Issue 12, December 2017}




\section{International Journal of Science and Research (IJSR) \\ ISSN (Online): 2319-7064}

Index Copernicus Value (2016): 79.57 | Impact Factor (2015): 6.391

\section{Conflicts of interest}

There are no conflicts of interest.

\section{References}

[1] John WO, Daniel C, Morris HF. Long-Term Assessment of Endosseous Dental Implants Placed in the Augmented Maxillary Sinus. Annals of Perio 2000;5:152-6.

[2] Assoian RK, Grotendorst GR, Miller DM, Sporn MB.Cellular transformation by coordinated action of three peptide growth factors from human platelets. Nature 1984;309: 804-6.

[3] Tajima N, Ohba S, Sawase T, Asahina I. Evaluation of sinus floor augmentation with simultaneous implant placement using platelet-rich fibrin as sole grafting material. Int j oral \&maxfac implants 2013;28:77-83,

[4] Kanayama T, Horii K, Senga Y, Shibuya Y. Crestal Approach to Sinus Floor Elevation for Atrophic Maxilla Using Platelet-Rich Fibrin as the Only Grafting Material: A 1-Year Prospective Study. Implant dent 2015;25:32-8

[5] Choukroun J, Diss A, Simonpieri A, Girard MO, Schoeffler C, Dohan SL et al. Platelet-rich fibrin (PRF): a second-generation platelet concentrate. Part $\mathrm{V}$ : histologic evaluations of PRF effects on bone allograft maturation in sinus lift. Oral Surg Oral Med Oral Pathol Oral RadiolEndod. 2006;101:299-303.

[6] Misch E C. Classification of bone density. Contemporary Implant Dentistry, 3rd edn. Missouri: Mosby Elseiver publishers; 2008. p. 130-45

[7] Klongnoi B, Rupprecht S, Kessler P, Thorwarth M, Wiltfang J, Schlegel KA. Influence of platelet-rich plasma on a bioglass and autogenous bone in sinus augmentation. An explorative study.Clin oral implants res 2006; 17:312-20.

[8] Schlegel KA, Zimmermann R, Thorwarth M, Neukam FW, Klongnoi B, Nkenke E, et al. Sinus floor elevation using autogenous bone or bone substitute combined with platelet-rich plasma. Oral Surg Oral Med Oral Pathol Oral RadiolEndod 2007;104:e15-25.

[9] Schaaf H, Streckbein P, Lendeckel S, Heidinger KS, Rehmann P, Boedeker RH, et al. Sinus lift augmentation using autogenous bone grafts and platelet-rich plasma: radiographic results. Oral Surg Oral Med Oral Pathol Oral RadiolEndod. 2008;106:673-78

[10] Tabassum A, Meijer GJ, Wolke JG, Jansen J A. Influence of the surgical technique and surface roughness on the primary stability of an implant in artificial bone with a density equivalent to maxillary bone: a laboratory study. Clin oral implants res 2009;20:327-32.

[11] Kim YK, Kim YJ, Yun PY, Kim JW. Effects of the taper shape, dual-thread, and length on the mechanical properties of mini-implants. The Angle orthodontist 2009;79:908-14.

[12] Lee SY, Kim SJ, An HW, Kim HS, Ha GK, Ryo KH, et al. The effect of the thread depth on the mechanical properties of the dental implant.J AdvProsthodont.2015; 7:115-21.
[13] Dos Santos MV, Elias CN, Lima CJH. The effects of superficial roughness and design on the primary stability of dental implants.Clin implant dent and rel res 2011;13:215-23.

[14] Tabassum A, Meijer GJ, Wolke JG, Jansen JA. Influence of surgical technique and surface roughness on the primary stability of an implant in artificial bone with different cortical thickness: a laboratory study. Clin oral implants res 2010;21:213-20.

[15] Khalfalla AE, Fahmy MH, El-Ashwah AA . Evaluation of sinus augmentation with simultaneous implant placement. Alexandria Dent Jour 2015;40:14047.

\section{Figures}

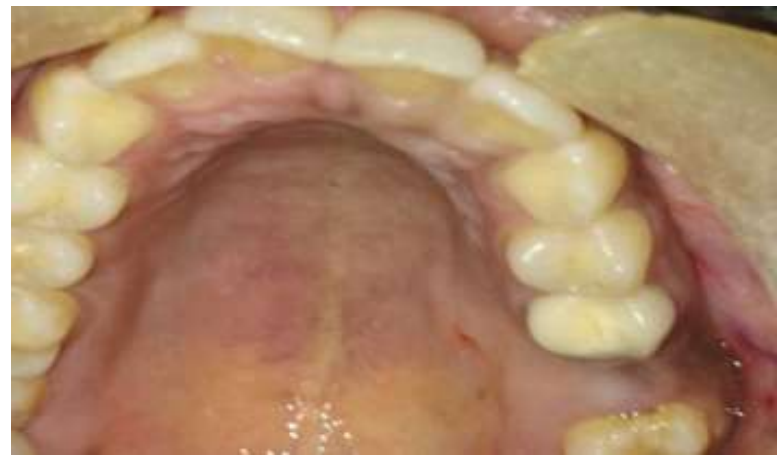

Figure 1: Pre-operative photograph (case 1)

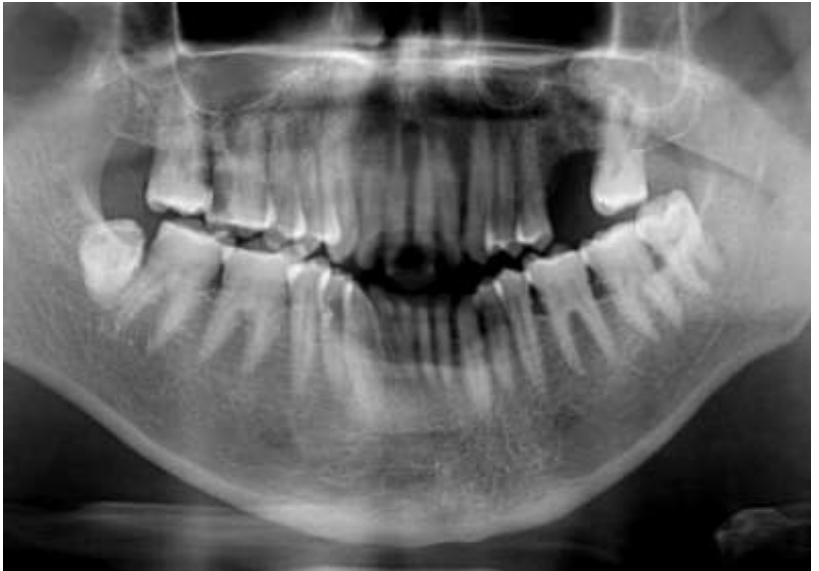

Figure 2: Pre-operative OPG radiograph (case 1)

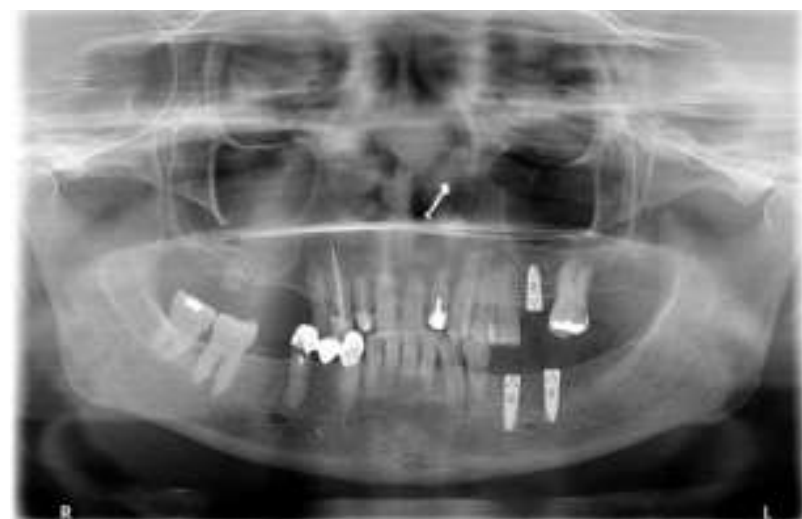

Figure 3: Pre-operative OPG radiograph (case 2).

Volume 6 Issue 12, December 2017 www.ijsr.net 


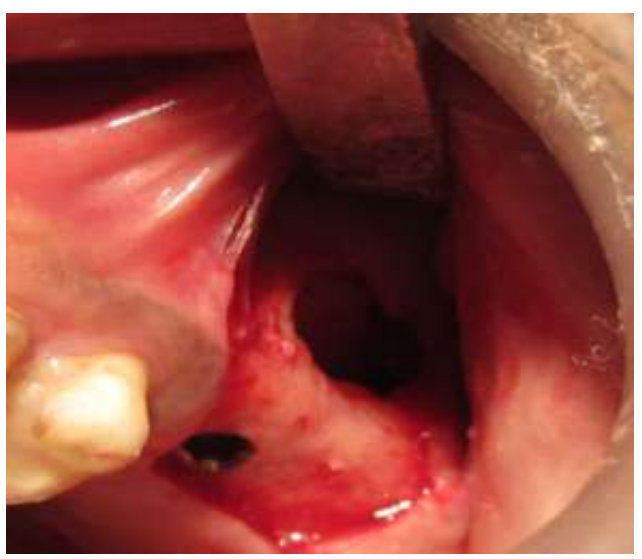

Figure 4: Lateral sinus osteotomy and simultaneous implant placement (case 1).

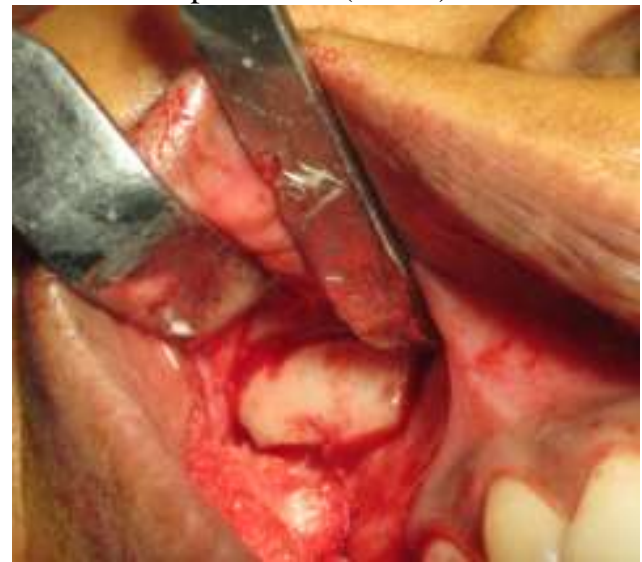

Figure 5: Lateral sinus osteotomy (case 2)

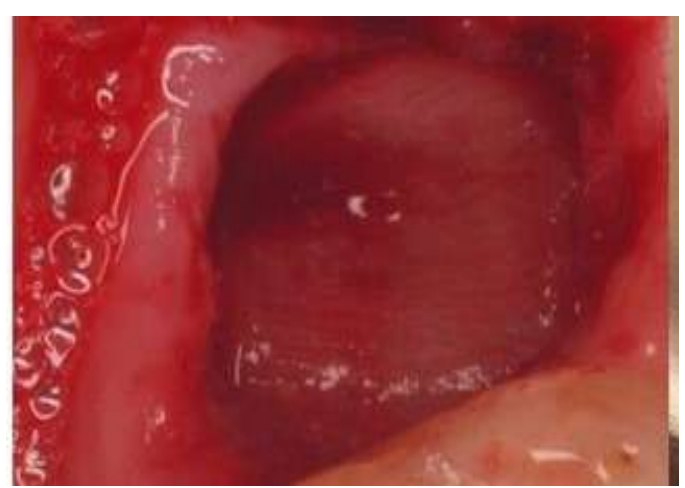

Figure 6: PRF membrane sealing the bone graft (case 1)

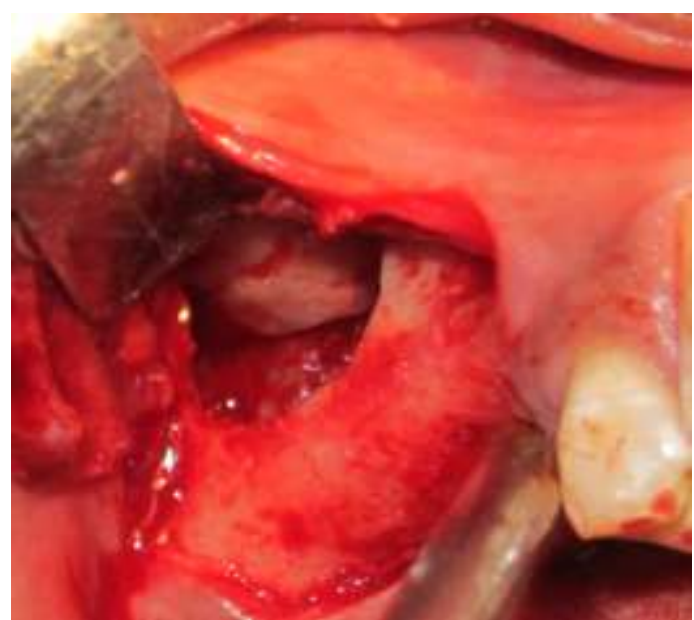

Figure 7: PRF membrane sealing the bone graft (case 2).

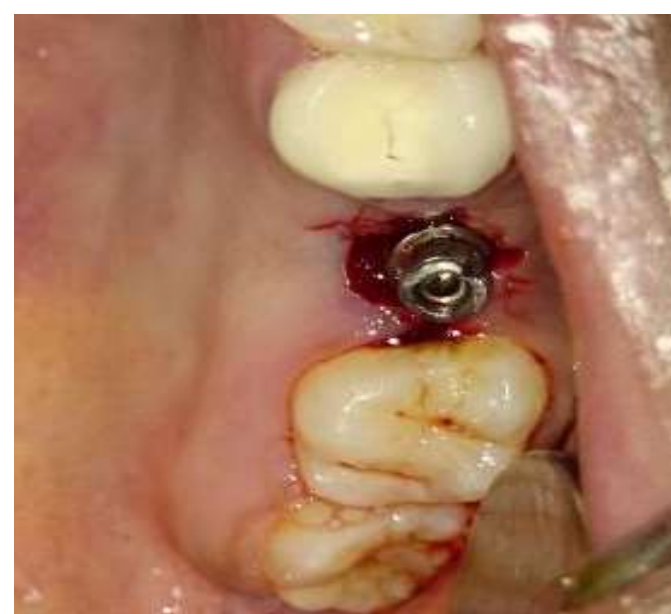

Figure 8: Placement of abutment (case 1)

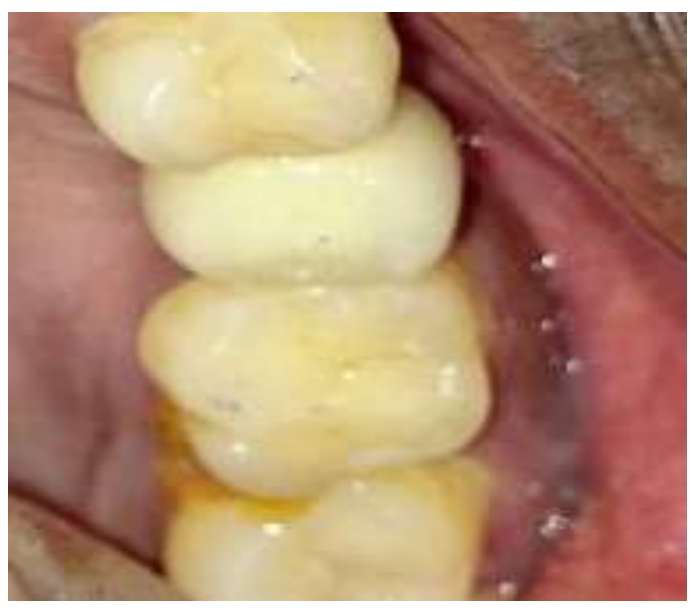

Figure 9: Placement of crown (case 1).

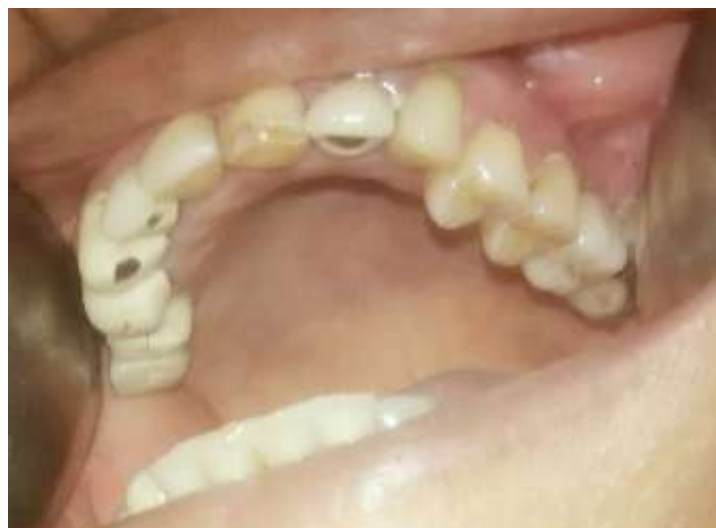

Figure 10: Placement of crown (case 2)

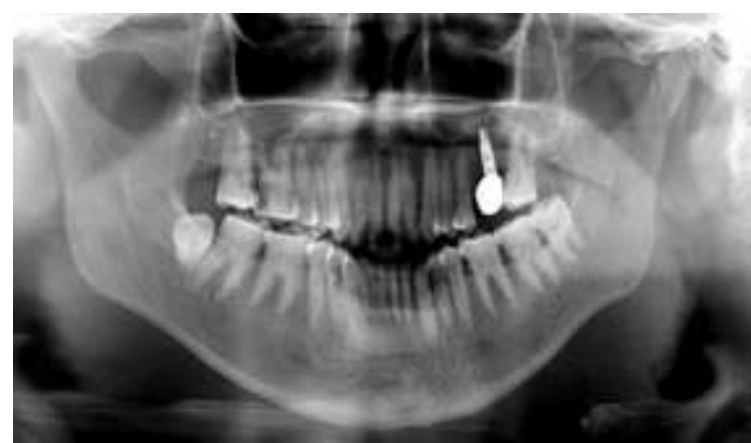

Figure 11: Post-operative OPG (case 1).

Volume 6 Issue 12, December 2017

www.ijsr.net

Licensed Under Creative Commons Attribution CC BY 


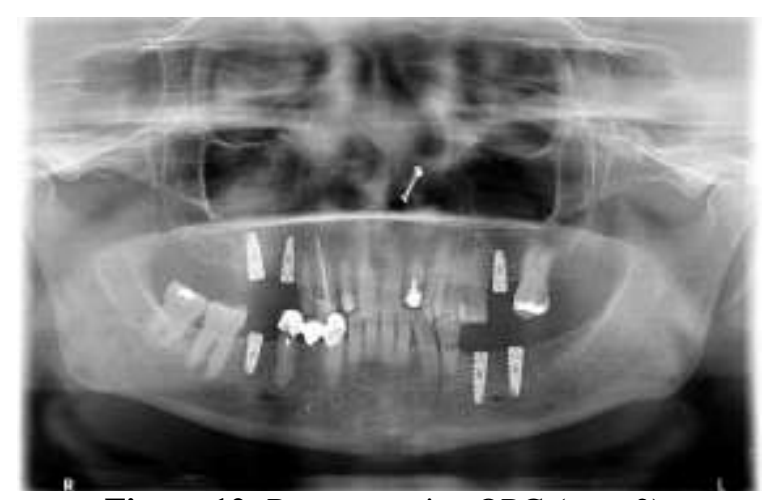

Figure 12: Post-operative OPG (case 2).

\section{Author Profile}

Dr. Mamthashri V, B.D.S, M.D.S, affiliated to Government Sental College and Research Institution, Bangalore. Interested field includes Oral and Maxillofacial Surgery and Research.

Volume 6 Issue 12, December 2017 www.ijsr.net 